Jorge AlCÁzAR

Universidad Nacional Autónoma de México

jorgealcazarbravo@hotmail.com

\title{
Intertextualidad narrativa: cómo Pacheco se apropia de The Go-Between
}

Uno de los rasgos que distinguen a las manifestaciones culturales posmodernas, ya sean fílmicas, literarias o televisivas, es el diálogo intertextual que a veces establecen tales manifestaciones. Umberto Eco entiende por diálogo intertextual a aquel fenómeno en el que en un texto dado se pueden identificar ecos de textos anteriores (197). En ese artículo, Eco reflexiona en torno a la literatura y la cultura de masas en términos de repetición, a la vez que esquematiza cuatro formas de repetición propias de la estética posmoderna. El primer tipo de repetición es la continuación (retake), cuando se recicla a los personajes de una historia previamente exitosa. Tal es el caso de novelas como Veinte años después, las obras de Updike protagonizadas por Rabbit, o las numerosas historias del ciclo artúrico que cuentan una y otra vez las vicisitudes de Lancelot, Perceval o Gawain. Después tenemos la reproducción (remake) que consiste en relatar o retomar de nuevo una historia previamente conocida. En el devenir literario hay legiones de Robinsones, Faustos, Dráculas y Don Juanes. La tercera categoría es la serie, fenómeno harto común en la cultura de masas, en la cual encontramos una situación fija y un restringido número de personajes, presentándonos de manera reiterada un esquema narrativo que permanece constante. Y por 
último tenemos la saga, una variante de la serie, que gira alrededor de una familia y sus cambios en el tiempo (200-201).

Otro crítico que nos plantea cuestiones semejantes es el comparatista Theodor Ziolkowski. En su estudio sobre La vida de Jesús en la ficción literaria (1972), propone que la acción de una narración moderna puede estar prefigurada en la estructura mítica de un texto previo, en la medida en que se puedan establecer paralelos entre ambos esquemas narrativos. Tal vez el caso más famoso de este proceso de transfiguración lo sea Ulysses de Joyce, obra en la que un Odiseo moderno de origen judío vaga por las calles de Dublín, reactualizando vagos detalles de la epopeya homérica. Como se puede ver, esto no implica apego incondicional a la fuente original ya que el texto "posfigurativo" se puede apartar, o sencillamente abstraerse por completo, del esquema de acción original. Cabe advertir que el esquema que subyace a esta propuesta se inscribe dentro de los parámetros establecidos por la interpretación bíblica llamada tipológica o figural. Erich Auerbach apunta al respecto: "La interpretación 'figural' establece una relación entre dos acontecimientos o personas, por la cual uno de ellos no sólo tiene su significación propia, sino que apunta también al otro, y éste, por su parte, asume en sí a aquél o lo consuma" (75).

Gérard Genette, a su vez, acuñó los términos hipotexto e hipertexto para dar cuenta de ese paso entre un texto base y otro que se monta en él y lo transforma. En su estudio seminal, Palimpsestos, publicado originalmente en 1983, trata de un dominio específico de la transtextualidad, denominado hipertextualidad, y define esta pareja de conceptos de esta manera: "Entiendo por ello toda relación que une un texto B (que llamaré hipertexto) a un texto anterior A (al que llamaré hipotexto) en el que se injerta de una manera" diferente a la del comentario crítico, como lo que hace Aristóteles al considerar, por ejemplo, a Edipo Rey (14). Así el hipertexto es un "texto derivado de un texto anterior", ya sea por transformación simple, como hace Joyce en Ulysses, al "transponer la acción de la Odisea al Dublín del siglo xx" (15); o por transformación indirecta, es decir una forma de imitación, como la realizada por Virgilio en la Eneida, ya que esta obra involucra una competencia genérica, inspirada de alguna manera en los modelos homéricos anteriores.

Julie Sanders, por su parte, ve estos fenómenos como variantes intertextuales de la adaptación o la apropiación, por parte de un creador - ya 
sea éste novelista, guionista o compositor - de un texto o de una obra anterior. La adaptación presupone, por lo general, un paso o cambio de una matriz genérica a otra, como sería la adaptación cinematográfica de una novela o una creación musical, digamos una ópera, basada en una pieza dramática; o incluso una tira cómica o una animación fílmica con una fuente literaria. Además tenemos casos en que una adaptación a la pantalla conlleva una doble transformación genérica como sucede en Las relaciones peligrosas (1988), película dirigida por Stephen Frears. El dramaturgo inglés Christopher Hampton realizó el guión, el cual, a su vez, está basado en su adaptación teatral de la novela epistolar de Choderlos de Laclos. En la terminología de Genette, estaríamos hablando de una doble transformación intermodal de varios sistemas semióticos: de la ficción literaria al espacio escénico y de allí al variado y sincrético lenguaje fílmico. La apropiación implica, por otro lado, adueñarse del esquema, la trama, la temática, así como de los motivos o detalles provenientes de un texto; éstos, a su vez, se presentan de manera novedosa, creando en el lector la sensación de estar leyendo un texto aparentemente original.

Entre los ejemplos que ofrece la autora, encontramos la novela de Graham Swift, Last Orders, ganadora del Booker Prize en 1996. Los miembros del jurado resaltaron la alta originalidad de la obra. Poco después, John Flow, un docente de la Universidad de Queensland en Australia, llamó la atención hacia las similitudes evidentes con la reconocida novela de William Faulkner As I Lay Dying. En la narración de Faulkner tenemos un peregrinaje por parte de los familiares de Addie Dundren, quienes llevan sus restos a Jefferson para darle santa sepultura. La novela está conformada por los monólogos de cada uno de ellos, incluyendo uno de la difunta en cuestión. En el caso de la obra de Swift, tenemos a un grupo de amigos que se trasladan a Margate para esparcir las cenizas del recién fallecido Jack Dodds. Esta obra narrativa también recurre al manejo del monólogo interior y, al igual que Addie Dundren, el carnicero quien ha pasado a mejor vida también nos ofrece el suyo propio. Todo esto desató una controversia sobre si una obra con semejantes paralelismos debía ser merecedora del tal premio. Incluso algunos jurados reconocieron no haber leído la obra de Faulkner. No faltaron otros novelistas que entraran a la palestra defendiendo a Swift. 
Julian Barnes adujo que el préstamo y la apropiación eran rasgos comunes del proceso artístico del novelista. ¿Nos encontramos ante un caso de plagio literario o ante el "homenaje" de un autor a otro, como arguyó el propio Swift? (Sanders: 32-35).

Todo esto nos habla del estatuto precario de la originalidad estética en el mundo de la creación posmoderna, donde a menudo el novelista mira hacia el pasado para alimentar el ímpetu creativo. No es infrecuente encontrar a figuras tutelares de la creación que se convierten en entes ficcionalizados. Ya sea aspectos de la vida de Flaubert en manos de Julian Barnes o de Henry James en la pluma de Colm Tóibín. O que el novelista recree figuras históricas como hace John Banville en su trilogía científica: Doctor Copernicus (1976), Kepler (1981) y The Newton Letter (1982). Tenemos también a Peter Ackroyd quien combina traslapes temporales, como es el caso de Hawksmoor (1985), tal vez su obra más reconocida, donde el lector salta, en capítulos alternos, entre el siglo XVIII y misteriosos asesinatos en el Londres moderno del xx. Estos crímenes tienen lugar en las cercanías de iglesias construidas por el arquitecto Nicholas Dyer - al servicio de Christopher Wren - narrador de los capítulos nones, quien también se ve envuelto en extraños ritos esotéricos; mientras que los capítulos pares se ubican en el presente vehiculados por un narrador omnisciente que se focaliza en varias voces y personajes, incluyendo al investigador Nicholas Hawksmoor. Asimismo se puede mencionar a Rose Tremain, ya sea recreando los vaivenes y vicisitudes de Robert Merivel, un cirujano en la corte de Charles II, en Restoration (1989) o la estancia de un laudista inglés, modelado en John Dowland, en el reinado de Christian IV en la Dinamarca de las primeras décadas del siglo XVII en su novela de 1999, Music and Silence.

El narrador debe echar mano de lo que pueda para documentar (para enraizar la ficción en lo real, habría dicho Barthes) ese estado pretérito alejado del presente y nunca estará ajeno a posibles imputaciones de hurto verbal. Ian McEwan, por ejemplo, fue acusado por un periódico dominical de haber plagiado la autobiografía de una enfermera durante la Segunda Guerra Mundial (No Time for Romance, de la autora popular en ese tiempo Lucilla Andrews) para la parte central de Atonement. A lo que el novelista contestó en una pieza periodística que llevaba por título "An Inspiration, yes. Did I copy from another author? No": 
after I finished the opening section, set in 1935, Dunkirk would have to be followed by the reconstruction of a 1940 London hospital. It is an eerie, intrusive matter, inserting imaginary characters into actual historical events. A certain freedom is suddenly compromised; as one crosses and re-crosses the lines between fantasy and the historical record, one feels a weighty obligation to strict accuracy (McEwan).

Obra de la que se enteró al hacer sus pesquisas en el Imperial War Museum, añadiendo que por supuesto le había dado a la autora el crédito correspondiente en la nota final de Atonement. Y cada vez se vuelve más frecuente encontrar este tipo de reconocimiento en las últimas páginas de muchas novelas. ¿Se puede imaginar el lector de qué tamaño habría sido una nota de esta índole, si Umberto Eco hubiera incluido algo semejante para El nombre de la rosa? Porque lo que hace Eco en esta novela rebasa con creces los procedimientos típicos del diálogo intertextual (guiño alusivo, pastiche o polémica oculta) propuestos por él que mencionamos antes. $\mathrm{Y}$ en las Apostillas posteriores al éxito comercial de su libro, Eco indicaba el parentesco un tanto engañoso con la novela gótica pero no hacía mención alguna de cómo se había aprovechado de los planteamientos de Mijaíl Bajtín sobre el papel de la risa en el mundo medieval para darle cuerpo y combustible apocalíptico a los argumentos de Jorge de Burgos, aquel portavoz ciego de los atavismos tradicionales y defensor a ultranza de la autoridad eclesiástica en $\mathrm{El}$ nombre de la rosa.

Como se puede anticipar, los fenómenos de la adaptación y la apropiación como los concibe Julie Sanders no son otra cosa sino modalidades y variantes del tipo de reescritura que se ha practicado a través de la estética posmoderna. Como se hará evidente en los casos subsecuentes, el novelista se apropia y adapta motivos y detalles de un hipotexto y los inserta en un nuevo universo ficcional, creando un hipertexto que parece a todas luces algo genuino y original pero que se ha aprovechado del texto de un autor distinto aparecido con anterioridad. Acerquémonos al primer hipotexto, The Go-Between, novela del año 1953, de H. P. Hartley y de la cual se vale, como trataremos de demostrar en las páginas restantes, José Emilio Pacheco para Las batallas en el desierto (1980). 
La oración inicial de The Go-Between enmarca y condensa el tema de la mirada retrospectiva: "The past is a foreign country: they do things differently there". El narrador Leo Colson, un hombre que rebasa los sesenta años empieza a recordar muy a su pesar al encontrarse con objetos remanentes de su infancia: "with the patina of age". Entre ellos está un diario con broche de seguridad cuya combinación logra abrir de la misma manera que lo hacía de niño asumiendo un estado de trance aparente con el que solía impresionar a sus compañeros en la escuela. Aquí se establece un rasgo de conducta que reaparecerá más adelante: la necesidad de crear un cierto efecto como si se estuviera ante un público en un escenario, marca distintiva de los nacidos bajo el signo de Leo. En el diario está depositada una carga emocional que le molesta y que asocia con la desilusión y el fracaso:

I looked away and it seemed to me that every object in the room exhaled the diary's enervating power, and spoke its message of disappointment and defeat. [...] and I felt with a bitter blend of self-pity and self-reproach, that had it not been for the diary, or what the diary stood for, everything would be different. I should not be sitting in this drab, flowerless room, where the curtains were not even drawn to hide the cold rain beating on the windows, or contemplating the accumulation of the past and the duty it imposed on me to sort it out. I should be sitting in another room, rainbow-hued, looking not into the past, but into the future: and I should not be sitting alone (Hartley: 8).

En la adaptación fílmica de Harold Pinter, para la producción de 1970 dirigida por Joseph Losey, se recupera y se condensa el motivo visual de la lluvia golpeando el cristal de una ventana, imagen con la que concluye el paso de los créditos. Empero, en el entramado de la película servirá para asociarlo, por medio de entrecortes momentáneos, que no cobran sentido inmediato para el espectador, con la vida grisácea del Leo adulto.

El diario tiene por fecha 1900 y el estar en los albores de un nuevo siglo produce unas expectativas excepcionales en el Leo de ese momento: la venida inminente de un futuro promisorio. En esas páginas se 
alude a su estancia veraniega en Norfolk, en la casa de un compañero del que ni siquiera a esas alturas parece recordar su nombre; diecinueve días que, después nos iremos enterando, lo han marcado de por vida. Pero antes nos presenta cómo interactuaba con sus compañeros, cómo consigue sobrevivir a sus burlas y conductas abusivas, y cómo logra imponerse a dos de ellos a través de la magia (un par de maldiciones escritas en su diario que están a un tris de producir resultados fatales) y así ganarse el respeto de los demás.

En ese prólogo rememorador se establece la disociación psicológica entre el adulto fracasado y el niño expectante ante lo que vendrá con la repetición de la interrogante "Are you vanquished, Colston, are you vanquished?"- la frase con que sus compañeros Jenkins y Strode lo asedian - pero que en sus reapariciones posteriores emana de la voz del niño de doce años que cuestiona al hombre mayor venido a menos, quien se ha mostrado incapaz de cristalizar tales expectativas. Ese niño con su propensión a imaginarse como el héroe del momento, a establecer jerarquías zodiacales, a inventar maldiciones en lenguajes crípticos inexistentes es la voz narrativa que se mezcla y confunde con el discurso del hombre adulto, dedicado a acumular datos, el bibliógrafo que cataloga los libros de los demás en lugar de escribir los suyos propios.

Al arribar a Brandham Hall, la casa de los Maudsley, Leo llega a un lugar del cual desconoce las dinámicas de interacción social. Marcus, su compañero de escuela, le dice que al cambiarse debe tirar la ropa para que sea recogida por los sirvientes. Al dirigirse a Lord Trimingham, lo hace como le habla a sus compañeros, por su apellido. Así, cuando él le dice que lo puede llamar Hugh, lo siente demasiado familiar; y cuando se entera de que es noble no sabe si llamarlo "Viscount". Más adelante las diferencias de clase se harán más notorias, especialmente durante el juego de cricket y en el convivio subsecuente. A lo largo de la novela el sentido de ciertas palabras le crean zonas de incertidumbre a Leo, el niño de doce años que presume de usar "long words" con sus condiscípulos. Dos en especial le acarrean grandes problemas de comprensión como veremos más adelante: "spooning" y "lady-killer".

En la arquitectónica de la novela, Leo se encuentra ante fuerzas e individuos que lo rebasan. Cuando Marian, la hermana de Marcus, pro- 
pone llevarlo a Norwich para comprarle un atuendo apropiado para el calor del verano, no se da cuenta de que ha sido utilizado para que ella pueda ver a su amante, Ted Burgess, quien por cierto renta una finca a Hugh Trimingham. Después que éste le pide que le dé un mensaje a Marian, la siguiente vez que se ven lo llama "Hullo, there's Mercury". Leo cree que se refiere al más pequeño de los planetas y no lo asocia con "el mensajero de los dioses", como explica Hugh. Así es como percibe a estas tres figuras, como si fueran fuerzas cósmicas o entidades zodiacales que al acercarlo hacia ellos o al pedirle que entregue recados o misivas lo engrandecen. No entiende cabalmente cómo se relacionan entre sí y se siente atraído hacia cada uno de ellos de manera distinta. A Marian la admira por su belleza y voluntad independiente; estaría dispuesto a hacer cualquier cosa por ella. A Hugh, por su bonhomía y ausencia de pedantería social, así como su experiencia en la guerra contra los Boers, que lo ha dejado con el rostro deformado. Después de oscilar entre rechazo y aceptación, Leo termina por sentir a Ted como alguien más cercano a él. Ambos vienen de estratos sociales inferiores al de los individuos con los que interactúan en Brandham Hall.

La manipulación de que es objeto, para seguir sirviendo de intermediario epistolar en el amorío ilícito entre Marian y Ted, no la reconoce al principio o sencillamente se niega a aceptarla. En esa fase inicial, tampoco parece darse cuenta de que él también está enamorado de Marian ni de su agonística posición en relación al Sagitario militarizado (Hugh) y el Acuario rústico (Ted) que antagonizan por los favores de esa Virgo (Marian), aparentemente inalcanzable. Por lo tanto saborea al máximo esos momentos de grandeza (desde su perspectiva infantil) inesperada cuando, al regreso de una salida a nadar, se vale de su traje de baño que no fue utilizado para secar la cabellera de Marian, o cuando ella le da un beso al comunicarle un mensaje de Ted.

Un momento de desencanto es cuando, después de justificar con su casuística escolar si se puede leer la correspondencia ajena, entrevé unas líneas de una misiva y se da cuenta de que Marian usa el lenguaje de los enamorados y, por lo tanto, incurre en la actividad de "spooning", lo cual lo deja desolado. Más adelante, una de las condiciones que le impone a Ted para seguir con su labor de mensajero es que le explique el alcance de dicho término. Ted considera que el indicado para dar tal 
explicación (como se diría de "the facts of life") es el padre y (como ya ha fallecido), con evasivas sólo atina a insinuar un símil: "It makes you feel on top of the world, if you know what that means" (176).

Leo siente que debe mantener a estos dos enamorados separados y recurre a la mentira (un hábito infeccioso en ese lugar) e incluso a un rito mágico valiéndose de una planta venenosa y a la vez atractiva con "lusty limbs": "Deadly Nightshade - Atropa Belladonna" (38), que crece en una zona abandonada de la casa. En otro momento, cuando deambula con Marcus por el lugar, la ve de esta manera:

But this plant seemed to be up to something, to be carrying on a questioning traffic with itself. There was no harmony, no proportion in its parts. It exhibited all the stages of its development at once. It was young, middle-aged, and old at the same time. [...] It invited and yet repelled inspection, as if it was harbouring some shady secret which it yet wanted you to know (192).

Anticipa lo que inmediatamente van a oír: el susurro hipnóptico de Ted dirigiéndose a su amada y que Marcus descalifica con su francés transliterante como "un couple qui fait le cuiller".

Como es de esperarse, el ritual mágico al que recurre Leo no logra su cometido ni tampoco evita el desencadenamiento abrupto de los sucesos. Al no aparecer Marian para entregar la bicicleta, el anticipado regalo para el cumpleaños de Leo, la Sra. Maudsley lo obliga a acompañarla en busca de su hija. Al encontrarlos en esa zona oscura de la propiedad lo que ven es a una pareja en plena cópula, lo cual provoca una crisis nerviosa en el niño y posteriormente el suicidio de Ted.

Podría pensarse que la novela está centrada en las percepciones fantasiosas e inmaduras de un niño que se acerca a la pubertad. La voz narradora de este niño-adulto sostiene el relato por cerca de trescientas páginas y a la vez recrea con lujo de detalles un mundo que ha desaparecido por completo para la Inglaterra de mediados del siglo xx. Vemos la mansión señorial de un aristócrata venido a menos como Lord Trimingham, quien tiene que rentarla a los Maudsley para mantener su tren de vida, mientras que ellos esperan poder concertar la boda con su hija mayor para beneficio de todos. También observamos los 
hábitos y actitudes en relación al vestido, el rezo o el comer; la interacción de las clases sociales bajo el barniz aparente de la equidad y el "fair play"; al igual que el microcosmos escolar con el lenguaje de los chicos y sus tácitos códigos de conducta. Y sobre todo accedemos al mundo interior de un niño con un yo-dividido cuyo nombre real es Lionel y no Leo, quien al estrenar y posar con su atuendo verde de verano exclama: "I feel quite another person" (49). Actitud semejante a la que siente cuando habla en ese francés pidgin con Marcus. Pero a la vez podemos anticipar al hombre que será a futuro: el que preferirá acumular datos y hechos concretos, dejando atrás el ámbito de la imaginación infantil. Que el niño prefigura al adulto lo podemos constatar en su meticulosidad por asentar cifras en su diario, ya sea las trece millas y media que se recorrieron de la estación ferroviaria a la casa o la consulta cotidiana del termómetro para verificar el aumento del calor o considerar el hechizo como algo semejante a los pasos que se siguen para realizar un experimento químico. Y esa actitud no difiere de sus dos grandes momentos de apoteosis: al atrapar el elevado de Ted en el juego de cricket y su éxito al cantar en el festejo en que se zanjan por un momento las diferencias sociales. Ambas actividades son ante sus ojos disciplinas que hay que cultivar: "My being was incandescent with a vision of angels, robes, virginity, and whiteness, eternally prolonged; and with the sensation of soaring that the music's slow ascent so powerfully evoked. But none of this, I think, got into my voice, for I regarded singing as a discipline no less than cricket: nothing of what one felt must be betrayed" (149).

Y aquí podemos identificar algo del sutil método narrativo de Hartley que, a través de la insinuación parcial, la alusión velada y la gradación de símbolos, hace que el relato avance sin contratiempos. Esto lo podemos ver desde el mismo epígrafe, tomado de la cuarta estrofa de un poema de Emily Brontë, "I saw thee child, one summer day":

But, child of dust, the fragrant flowers,

The bright blue sky and velvet sod

Were strange conductors to the bowers

Thy daring footsteps must have trod.

(Brontë) 
Pero podría aventurarse la hipótesis de que estos versos dicen algo (en razón del entorno campestre donde transita Leo al entregar los mensajes) y tal vez no tematizan lo suficiente la problemática que hemos venido considerando como lo hubiera indicado la estrofa anterior:

The anxious prayer was heard and power

Was given me in that silent hour

To open to an infant's eye

The portals of futurity.

(vv. 9-12)

Ya que en el epílogo de la novela, el hombre mayor logra encontrar, entre tantos objetos acumulados, la última carta que no fue entregada. Allí se entera de que la bicicleta, el obsequio de Marian para su décimo tercer cumpleaños, era realmente para facilitar el flujo de misivas entre Brandham Hall y la granja. Días después decide visitar el poblado y por casualidad conoce al joven Edward Trimingham, quien guarda gran parecido con Ted. A través de él logra ver a su abuela. Aislada del mundo y envuelta en sus recuerdos, la añosa Marian tiene una última encomienda para él: comunicar a su nieto de dónde viene y despejar sus dudas y escrúpulos hacia ella, ya que todo se debe a un acto de amor, al que debe entregarse llegado el momento y no aislarse como ha sido el hado del propio Leo.

\section{Carlos, el enamorado precoz o la historia social del alemanismo}

Hugo J. Verani señala en un penetrante ensayo sobre Las batallas en el desierto: "Una tendencia dominante de la producción tanto lírica como narrativa de Pacheco es la de mantener un diálogo con textos anteriores, propios y ajenos, que en algunas obras funcionan como subtexto [...] y en otras sólo sirven de trasfondo temático" (269).

Teniendo presente esto, preguntémonos qué conlleva que un novelista incluya como epígrafe la manera en que abre The Go-Between: The past is a foreign country. They do things differently there. Amén de los cambios de puntuación, ¿ello nos permitiría identificar una afinidad 
electiva hacia el relato de Hartley? Para Genette el epígrafe forma parte del ámbito que rodea a la obra, la dimensión paratextual, y puntualiza la más conocida de sus funciones: "consiste en un comentario del texto, que precisa o subraya indirectamente su significación" (2001: 134). Tratemos de identificar algunos elementos comunes entre estas dos novelas.

The Go-Between recrea un mundo victoriano que ya no existe y que puede ubicarse unos 52 años antes del inicio de la novela. Por su parte, en Las batallas en el desierto la acción se retrotrae unos 32 años y si aceptamos los indicios de lo que se oía en la radio, como "Amorcito corazón" (el consabido tema de Nosotros los pobres, compuesto por Manuel Esperón), si cotejamos el año de nacimiento del autor (1939) y la edad de Carlos el protagonista (nueve años), si revisamos el año de publicación original de la obra en el suplemento Sábado de Unomásuno (7 de junio de 1980) y la pista sembrada al final del texto, se podría llegar a la conclusión de que la acción inicia allá por el año de 1948, en plena etapa alemanista. Apareció como libro un año después bajo el sello de Era y el autor realizó ligeras modificaciones para la segunda edición de 1999, con las que hizo más evidente la lejanía del contexto novelesco en relación al presente de sus posibles lectores.

Si en The Go-Between se dedica buena parte de las quince páginas del prólogo a recrear la resistencia psicológica de Leo a rememorar lo ocurrido en el verano de 1900, en la novelita de Pacheco esto se apura en el enunciado inicial: "Me acuerdo, no me acuerdo: ¿qué año era aquél?" (9) Al igual que en el texto de Hartley, la voz narrativa amalgama dos tipos de discurso. Como señala Verani:

En Las batallas en el desierto se oyen, constantemente indiferenciadas, la voz del adulto que comunica la visión madura de los hechos y la voz del niño incapaz de dilucidar la situación vivida. Pacheco funde sutilmente dos órdenes temporales y dos perspectivas: la voz de Carlitos penetra el espacio textual con sus propias palabras, yuxtapuestas a las de Carlos, suscitando una contaminación de hablas de la cual emana la ironía y la riqueza lírico-sugestiva de la obra (264).

A la novela de Pacheco migran de alguna manera varios elementos y motivos que hemos identificado en el hipotexto base. El más inme-

112 AlCÁZAR / Intertextualidad narrativa: cómo Pacheco se apropia de The Go-Between 
diato es el ambiente de la escuela primaria donde estudia Carlos. Allí encontramos el antagonismo propio de los niños, las fricciones de orden social y de raza (el protagonista tiene un compañero de Japón, otro de padre estadounidense, a otro, de apellido Rosales, lo insulta con "indio pendejo"), la vergüenza de no saberse comportar en la mesa y que se lo hagan notar como le sucedió a Carlos un año antes al visitar la casa de Harry Atherton en Las Lomas. Asimismo nos topamos con los chismes que se tejen alrededor de la gente. Ahora frecuenta a Jim que se ufana de los logros de su Señor padre en el gobierno de Miguel Alemán. En la escuela se dice otra cosa: que ése no es su papá y que la mamá es tan sólo su querida en turno.

En una ocasión Jim lo invita a merendar al departamento. La joven mamá le ofrece algo diferente a lo que está acostumbrado Carlos:

¿Qué te parecen? Les dicen Flying Saucers: platos voladores, sándwiches asados en este aparato. Me encantan, señora, nunca había comido nada tan delicioso. Pan Bimbo, jamón, queso Kraft, tocino, mantequilla, ketchup, mayonesa, mostaza. Eran todo lo contrario del pozole, la birria, las tostadas de pata, el chicharrón en salsa verde que hacía mi madre (Pacheco: 29).

Al igual que la sandwichera espacial, Jim tiene una colección de plumas atómicas, juguetes importados y lee cómics en inglés que la joven mamá le compra en Sanborn's. Todo esto nos indica el inicio de la americanización de la vida en México, que obliga al padre de Carlos a aprender inglés a través de discos cuando tiene que trabajar para la compañía de detergentes que ha absorbido su antigua fábrica de jabones. Un periodista de origen estadounidense que creció en la capital pinta así el panorama:

Vestiges of a slower-paced traditional life, however, were being overwhelmed by Americanization. Luxury hotels catered to armies of visitors from the United States who were first drawn south in large numbers during World War II when Europe became inaccessible. The tourist trade emerged as the largest industry in Mexico, and spearheaded an American economic and cultural invasion. [...] Throughout the capital, fast-food outlets serving hamburgers, hot dogs, and pizza vied with taco stands. Baseball crowds rivaled those at bullfights and soccer matches. Super- 
markets stored their shelves with Kellogg's Rice Krispies, Campbell's soups, Coca-Cola, Heinz catsup, and Van Camp's Boston baked beans. Neon signs flashed a lexicon of U. S. corporate names: Ford, General Motors, Chrysler, Zenith, General Electric (Kandell: 486).

Esto se percibe desde el inicio de la novela:

Empezábamos a comer hamburguesas, pays, donas, jotdogs, malteadas, áiscrim, margarina, mantequilla de cacahuate. La Coca-Cola sepultaba las aguas frescas de jamaica, chía, limón. Los pobres seguían tomando tepache. Nuestros padres se habituaban al jaibol que en principio les supo a medicina. En mi casa está prohibido el tequila, le escuché decir a mi tío Julián. Yo nada más sirvo whisky a mis invitados: hay que blanquear el gusto de los mexicanos (Pacheco: 12).

La noche de la merienda Carlitos se enamora de la joven y hermosa mamá, a quien no puede dejar de mirar. Se llama Mariana, lo que le confiere una cercanía paronomásica con el de Marian. Quiere atesorar ese momento, mismo que queda emblematizado en un bolero (no el de Ravel con el que daban inicio las transmisiones de la XEQ ni las canciones infantiles de Cri Cri a las que estaba acostumbrado, sino de origen puertorriqueño) que se cita desde el inicio de la novela sin ser identificado explícitamente: "Por alto esté el cielo en el mundo, por hondo que sea el mar profundo, no habrá una barrera en el mundo que mi amor profundo no rompa por ti” (10). Éste es un procedimiento estructural del cual también se vale Hartley en The Go-Between. En el convivio posterior al juego de cricket se interpretan canciones; la mayoría de éstas se relacionan simbólicamente con la problemática por la que atraviesan los personajes. Por ejemplo, Ted canta, acompañado al piano por Marian a quien finge no conocer sino de vista, una tonada de The Bohemian Girl (1843) del compositor irlandés Balfe.

When other lips and other hearts

Their tales of love shall tell

In language whose excess imparts

Their power they feel so well. 
Leo observa la reacción de los oyentes ante "this resigned and mellifluous presage of infidelities to come, unaware of its underlying bitterness" (Hartley: 144). Pero en la novela no se incluye esta línea: "And you'll remember me" que hace patente la actitud de Ted ante las circunstancias presentes.

Si en The Go-Between la llegada del nuevo siglo presagia todo tipo de oportunidades, en la novela de Pacheco lo que se recalca es la burbuja comunicacional que sobredimensiona los supuestos logros de Miguel Alemán, "El Cachorro de la Revolución", y su gabinete de universitarios que intentaban ser un parteaguas en la historia de México.

Para el impensable año dos mil se auguraba —sin especificar cómo íbamos a lograrlo- un porvenir de plenitud y bienestar universales. Ciudades limpias, sin injusticia, sin pobres, sin violencia, sin congestiones, sin basura. Para cada familia una casa ultramoderna y aerodinámica (palabras de la época). A nadie le faltaría nada (11).

La versión original decía: "Para el impensable año 1980 [...]", 1o cual reducía el arco temporal de esta utopía tercermundista. Carlos registra la continua suspensión de clases para asistir a todo tipo de inauguraciones de obra pública. Sin embargo, también constata: "Por regla general eran nada más un montón de piedras. El presidente inauguraba enormes monumentos inconclusos a sí mismo" (16), mientras los alumnos permanecían parados por horas al sol.

A Miguel Alemán, el historiador Enrique Krauze lo caracteriza como el presidente empresario; y en efecto, su monografía La presidencia imperial detalla cómo en septiembre de 1927 se creó el grupo H-1920, en alusión al año en que ingresó a la Escuela Nacional Preparatoria:

Estamos dispuestos, y así lo juramos por lo más sagrado, en la lucha tremenda de la vida y a no escatimar un solo átomo de fuerza para levantar a aquél a quien el destino le sea adverso o se vea en un momento dado urgente de ayuda. Muchos de nosotros, y tenemos fe en ello, llegaremos a ocupar prominentes lugares en nuestra vida social y política, ellos quedarán obligados para ayudar a aquellos que lo necesiten del grupo (citado en Krauze: 90). 
Una de las estrategias que siguieron el grupo de jóvenes abogados para enriquecerse rápidamente fue el de urbanizar, para ello se creó Fraccionamientos México. Así adquirieron viejas haciendas en lugares como Cuernavaca, el rancho de Polanco o el rancho Los Pirules que llegaría a ser Ciudad Satélite (Krauze: 92). En la novela se recalca que el supuesto padre de Jim fue compañero de banca del presidente Alemán y está involucrado en varios de sus negocios, "el ganador de millones y millones a cada iniciativa del presidente: contratos por todas partes, terrenos en Acapulco, permisos de importación, constructoras, autorizaciones para establecer filiales de compañías norteamericanas" (Pacheco: 18).

Cuando los condiscípulos de Jim atacan a su padre, él se defiende aduciendo que lo ve poco porque "siempre está fuera, al servicio de México":

Sí cómo no, replicaba Alcaraz: "trabajando al servicio de México": Alí Babá y los cuarenta ladrones. Dicen en mi casa que están robando hasta lo que no hay. Todos en el gobierno de Alemán son una bola de ladrones. Ya que te compre otro suetercito con lo que nos roba (20).

Como buen conocedor de la historia de México, Pacheco está aludiendo puntualmente al tipo de comentarios que circulaban por esos años en carpas y teatros. Así en uno de sus sketches políticos, Jesús Martínez, "Palillo", como buen fustigador de "los políticos inmorales" se burlaba de ellos.

Lo que no podía decirse por escrito y en público, se hacía público a través de las cadenas del rumor, como estos versos contra Alemán y su grupo, compuestos luego de que dejó la presidencia:

Alí Babá con sus cuarenta ratas ha dejado a este pueblo en alpargatas. Pero el sultán se siente muy feliz gastando sus millones en París.

Si un nuevo sol en las alturas brilla, ¡maldito sea el sultán y su pandilla!

(Krauze: 113) 
En un momento de arrebato, Carlitos se escapa de la escuela, va a visitar a Mariana y declara estar enamorado de ella. Ella, con tiento y viveza, le hace ver que eso no se puede dar y lo despide con un beso, esperando que ese estado de infatuation "no se convierta en un problema para ti, en un drama capaz de hacerte daño toda tu vida" (Pacheco: 38); tal como sucede precisamente en The Go-Between. El incidente desencadena una serie de actos perversos y represivos. Jim adivina lo que ha sucedido y no quiere saber de él. En casa se le ve como un monstruo y se le lleva con unos especialistas que no atinan a explicar su caso; un sacerdote le pregunta cosas que rebasan su horizonte vivencial, “¿Has tenido malos tactos? ¿Has provocado derrame?” (43). Como apunta Verani: "Dos órdenes entran en conflicto: el puro e inocente mundo de la infancia y el deformado y corrupto mundo de los adultos" (266).

La manera en que cierra el relato trae nueva información. Al encontrarse por casualidad a Rosales vendiendo chicles, sabe por boca de él que Mariana se suicidó, parece, a raíz de externar una crítica al sistema en una reunión: "Al Señor no le gustó que le alzara la voz allí delante de sus amigos poderosísimos: ministros, extranjeros millonarios, grandes socios de sus enjuagues, en fin. Y la abofeteó enfrente de todo mundo y le gritó que ella no tenía derecho a hablar de honradez porque era una puta" (62).

Aquí podemos identificar una inversión en relación al hipotexto. En la novela de Hartley, el que se suicida es el amante Ted. Sin embargo, comparten un elemento en común, ambos actantes no parecen embonar en ese mundo de apariencias y falsedades.

Las últimas páginas de Las batallas en el desierto avanzan, en términos de temporalidad, a pasos agigantados. Carlos se da a la tarea de averiguar infructuosamente si Mariana realmente murió. Sus frases finales nos dan a entender que han transcurrido décadas. "Todo pasó como pasan los discos en la sinfonola. Nunca sabré si aún vive Mariana. Si hoy viviera tendría ya ochenta años" (68). En la edición original, la oración final reza así: "Si viviera tendría sesenta años". Con estos ajustes José Emilio Pacheco logra que la distancia temporal entre el acto de la enunciación narrativa y los hechos narrados coincidan cabalmente - con The Go-Between - en los cincuenta y dos años que los separan. 


\section{BIBLIOGRAFÍA}

Auerbach, Erich. Mimesis. México: Fondo de Cultura Económica, 1950.

Brontë, Emily. The Complete Poems. Janet Gerazi (ed.). Harmondsworth: Penguin, 1994.

ECO, UMBERTO. "Innovation \& repetition: between \& postmodern aesthetics", en Doedalus, 134:4, Fall 2005: 191-207.

Genette, GÉrard. Palimpsestos. Trad. Celia Fernández Prieto. Madrid: Taurus, 1989.

Genette, GÉRARd. Umbrales. Trad. Susana Lage. México: Siglo XXI, 2001.

Hartley, L. P. The Go-Between. Harmondsworth: Penguin, 1973.

Kandell, Jonathan. La Capital: The Biography of Mexico City. New York: Random House, 1988.

Krauze, EnRIQue. La presidencia imperial. México: Tusquets, 1997.

McEwan, IAN. "An inspiration, yes. Did I copy from another author? No", en The Guardian. Artículo en línea disponible en <http://www.theguardian. com/uk/2006/nov/27/bookscomment.topstories3 $>$ [fecha de consulta: 12 de julio de 2015].

Pacheco, José Emilio. Las batallas en el desierto. México: Era, 3ra. ed., 2011. SANDERS, Julie. Adaptation and Appropriation. London: Routledge, 2006.

Verani, Hugo J. "Disonancia y desmitificación en Las batallas en el desierto", en Verani, Hugo J. (ed.). La hoguera y el viento. José Emilio Pacheco ante la crítica. México: Universidad Nacional Autónoma de México, Difusión Cultural/Era, 1993: 263-273.

Ziolkowski, Theodor. La vida de Jesús en la ficción literaria. Caracas: Monte Avila, 1972. 